\title{
Humans, animals and computers: Minding machines?
}

\section{¿Humanos, animales y computadores: máquinas pensantes?}

Edward A. Wasserman ${ }^{1}$

\begin{abstract}
Are there minding machines? In this paper, I consult historical, philosophical, and empirical materials in trying to answer this intriguing question. My historical and philosophical discussions focus on five famous Frenchmen (Michele de Montaigne, René Descartes, Salomon de Caus, Julien Offray de La Mettrie, and Jacques Vaucanson) and one famous American (William James). My review of empirical research focuses on four topics in contemporary comparative cognition: associative/causal learning, shortterm memory, number discrimination, and metacognition. I conclude that minding machines do exist; they are humans and animals. Minding may be said to mediate the complex changes in behavior that humans and animals exhibit. However, computers and other mechanical devices are pale replicas that are built from the "wrong stuff." They will never attain the status of minding machines.
\end{abstract}

Key words: comparative cognition, associative/causal learning, shortterm memory, number discrimination, metacognition.

\section{Resumen}

¿Hay máquinas pensantes? En este artículo consulto material histórico, filosófico y empírico, tratando de responder esta intrigante pregunta. Mi discusión histórica y filosófica revisa el pensamiento de cinco famosos franceses (Michele de Montaigne, René Descartes, Salomon de Caus, Julien Offray de La Mettrie y Jacques Vaucanson) y de un famoso americano (William James). Mi revisión de investigaciones empíricas se focaliza en cuatro temas contemporáneos en cognición comparada: aprendizaje asociativo/causal, memoria de corto plazo, discriminación numérica, y metacognición. Concluyo que existen máquinas pensantes, ellas son los humanos y los animales. El acto de pensar, podría ser dicho, media los complejos cambios en el comportamiento que muestran humanos y animales. Sin embargo, computadores y otros dispositivos mecánicos son pálidas réplicas que están construidas con "el material equivocado". Nunca lograrán el estatus de máquinas pensantes.

Palabras clave: cognición comparada, aprendizaje asociativo/causal, memoria de corto plazo, discriminación numérica, metacognición.

1 Comparative Cognition Laboratory, Department of Psychology, University of Iowa. Iowa, Estados Unidos. ed-wasserman@uiowa.edu 
In the New York Times of November 11, 2003, the 25 most provocative questions facing science were enumerated. Three of them are of special importance to psychological science. Number 4: How does the brain work? Number 14: Can robots become conscious? And, Number 16. Are animals smarter than we think?

In the present paper, I will touch upon these three key questions while considering one overarching query: Are there minding machines? In attempting to answer this question, I will broadly interpret the terms "minding" and "machine" in my discussion of minding in humans, animals, and computers (for more on the excesses of mentalistic interpretation, see Wasserman \& Zentall, 2006a).

I appreciate the daunting subject of this paper. So, I will consult historical, philosophical, and empirical materials in trying to shed light on the nature of "minding machines." My historical and philosophical discussions will focus on five famous Frenchmen (Michele de Montaigne, René Descartes, Salomon de Caus, Julien Offray de La Mettrie, and Jacques Vaucanson) and one famous American (William James). And, my review of empirical research will focus on four especially interesting topics in contemporary comparative cognition: associative/causal learning, shortterm memory, number discrimination, and metacognition. Following these discussions and reviews, I will offer a few observations and analyses.

\section{Historical and philosophical discussion}

Before considering any experimental evidence, it may be helpful to provide some perspectives in the history of behavioral science and the philosophy of mind. So, let me now move to those notable individuals whose work will inform our later discussion.

\section{Montaigne}

Michele de Montaigne (1533-1592) was a Renaissance essayist. Although Montaigne was originally schooled as a lawyer, the character of his writings has led to his being known as a philosopher or a "skeptical thinker". The work that is most pertinent to us here is his famous Apologie de Raymond Sebond (1580/2003), in which he critically considered the relationship between humans and animals. 
Of humans, Montaigne wrote that presumption is our natural and original infirmity. Of all of earth's many creatures, we are the most miserable and frail; yet, we are also the most arrogant. That arrogance leads us to ascribe divine attributes to ourselves and to separate ourselves from all other creatures.

Montaigne raised penetrating questions about this arrogant placement of humans apart from and above animals. Is it really so easy to say with certainty what sets humans apart from animals? And, by what comparison between them and us do we ascribe brutishness only to them? Montaigne believed that skeptical inquiry into animal behavior can answer these two profound questions (Silver, 2002).

Montaigne's own skeptical inquiry into animal behavior dealt mainly with what he found in ancient texts, which suggested that animals: communicate socially, exhibit some forms of craftsmanship, and display some signs of logical decision making. In evaluating the dichotomy between animals versus humans, Montaigne adopted the following rule: From like results we must infer like faculties. This logic prompted Montaigne to conclude that human communication and reasoning cannot be firmly distinguished from animals' perhaps less advanced abilities (Gunderson, 1964). Thus, humans and animals must obey the same laws of nature, leading to the humbling position that there is no special place for humans among all of nature's creatures (Melehy, 2005; Silver, 2002).

\section{Descartes and Caus}

René Descartes (1596-1650) offered a dramatically different view of humans and animals. Of course, Descartes was the most celebrated French philosopher. He was also a mathematician and an anatomist. And, he famously espoused the philosophical doctrine of mind-body dualism.

In order to properly appreciate Descartes' position on mind and body, we have to expand our consideration to: humans, animals, and machines. Machines played a particularly prominent part in shaping Descartes' views.

As did many others of his time, Descartes visited several famous gardens in Europe. One of these gardens was in Saint-Germain-en-Laye, 
only 12 miles from Paris. There, amazing automatons (self-operating machines) were featured. Many of these marvelous devices were fabricated by Salomon de Caus.

Caus (1576-1626) was an engineer, who designed hydraulic automata for the grottoes in Saint-Germain-en-Laye and in many other European venues. Those hydraulic automata were the source of considerable fame and fortune for designers like Caus. These designers carefully concealed the designs of their machines; to have revealed these secrets would have deprived the spectators of their sense of wonder and denied the designers their lucrative livelihoods.

Descartes was especially fascinated by these hydraulic machines. But, beyond this fascination, Descartes saw real scientific possibilities for understanding the design of these machines. So, he sought to reveal the secret workings of these human creations; and, he later deployed the same investigative methods to divulge the secret workings of nature's creations.

Focusing on the operating properties of machines in his Discours de la méthode: Météores (1637/Adam \& Tannery, 1908), Descartes focused his talents and energies on the rainbow fountain: a notable wonder of the Renaissance garden in which a fine mist of water was sprayed skyward to catch the sunlight and to produce a rainbow on demand. This machine was to serve as a test case for Descartes' scientific method, which he deployed in order to understand the workings of the rainbow fountain through experiment and mathematics (Werrett, 2001).

That test proved to be highly successful. It was so successful that divulging the workings of this artificial device actually led to Descartes' explaining natural rainbows, thus prompting his conviction that all rainbows — whether natural or artificial — were produced by the same mechanical principles involving the reflection and refraction of light. Descartes thus concluded that all of nature may be a glorious machine - vastly more complex and on a far grander scale than any human contrivance.

Descartes discussed the nature of humans in his famous Traite de l'homme (1632/1972). There, he proposed that humans too are machines. But, we are vastly more intricate than hydraulic automata. Unlike machines, humans are capable of thought and language. Critically, we 
have an immaterial "rational soul," existing outside of the body and only influencing bodily movement via the pineal gland.

Descartes discussed the nature of animals in his famous Letter to the Marquess of Newcastle (1646/Ariew, 2000). There, Descartes argued that animals are purely beastly mechanisms - bête-machines (Gunderson, 1964; Newman, 2001). Animals do have sensations and passions; but, these are merely organic reactions. Animals lack thought and language. Animals lack abstraction and metacognition (Smith, 2005). And, animals have no mind or "rational soul" (Avramides, 1996).

Contrasting animals versus machines, Descartes contended that animals are mindless bodies like machines. So, he put animals into the category of automata and insisted that they behave mechanically - just like clocks (Erion, 2001). Contrasting animals versus humans, Descartes conceded that humans and animals are both organic machines. But, he argued that humans are special. We also have language and reason, whereas animals do not. Reason - what Descartes also called the universal instrument (Wilson, 1995) — allows humans to respond flexibly to any and all conditions as well as to attain mastery over nature (Melehy, 2005).

\section{La Mettrie and Vaucanson}

Julien Offray de La Mettrie (1709-1751) was a physician and a philosopher. His materialist ideas were at odds with the prevailing religious notions that were foundational to Descartes' dualism. La Mettrie too had interesting and important things to say about humans, animals, and machines.

La Mettrie agreed with Descartes that animals were machines. He also agreed with Descartes that animals had no souls. But, La Mettrie pursued Descartes' idea of the bête-machine to its logical end: l'homme machine (1747/1996). Daringly, La Mettrie believed that humans too are machines which also had no souls.

What did La Mettrie see as the relationship among humans, animals, and machines? Humans do not essentially differ from animals. Humans and animals are highly complex machines, whose matter and organization produce: life, feelings, intelligence, and consciousness 
(Gunderson, 1964; Vartanian, 1993). La Mettrie believed that nature created these biological machines with even more elaborate art than Jacques Vaucanson crafted his automatons.

Jacques Vaucanson? Yes, another engineer was to have a significant influence on psychological science!

Vaucanson (1709-1783) was an engineer who turned the mechanistic ideas of La Mettrie and Descartes into technical reality (Wood, 2002). Vaucanson set out to create what he called a moving anatomy —anatomie mouvante. The automata that he constructed have been considered to represent philosophical experiments (Riskin, 2003b) which sought to answer two intriguing questions. Which aspects of real creatures can be reproduced in machinery? What do such automata reveal about real creatures?

Vaucanson's prime creation was a mechanical duck, which became the most talked-about bird in all of Europe. Vaucanson became quite rich as a result of exhibiting the duck and his other automata. Indeed, Vaucanson was even elected to L'Academie des Sciences as an "Associated Mechanician", a position that was created solely to honor him.

What was so special about Vaucanson's mechanical duck? It had a weight-powered mechanism of over 1,000 movable parts that was hidden inside the bird and its pedestal. Each wing had over 400 articulated pieces. And, the duck's many and varied actions included: drinking, dabbling, gurgling, rising, crouching, stretching and bending its neck, and moving its wings, tail, and feathers. All of this was very well and good. But, the duck's greatest claim to fame was that it ate grain and, after a suitable delay, it defecated. Good show!

Vaucanson's famous avian automaton is sometimes called: $\mathrm{Le} C \mathrm{C}$ nard Digérateur or The Digesting Duck. But, this moniker turns out to be a flagrant misnomer. The duck did not digest food at all —it was a fraud! The ingested food actually progressed no farther than the base of the duck's neck. Fake excrement - that had earlier been loaded into a hidden repository near the duck's tail — was expelled after a programmed postprandial delay. The debunker of the duck was none other than Jean Eugène Robert-Houdin, another famous French mechanician and magician (Riskin, 2003a). 
Today, instead of mechanical ducks imitating real ones, computerized creatures like AIBO — the dog-like robot manufactured by the Sony Corporation - are becoming increasingly lifelike. We may not be fooled by this most recent charade, but real dogs may have been tricked when they were allowed to interact with AIBO (Kubinyi, Miklósi, Kaplan, Gácsi, Topál \& Csányi, 2004).

In a recent essay, Riskin (2003b) suggests that Vaucanson's Duck has commanded so much attention for so long because it dramatizes two contradictory claims: (a) Animals are merely machines. (b) Animal life is irreducible to mechanism. Because this tension persists, Riskin proposes that we still live in the age of Vaucanson. We are continuing a project that began 250 years ago by the Digesting Duck that didn't.

Beyond these philosophical issues, Vaucanson's Duck poses a very practical problem for comparative psychology: How can we discriminate profound from superficial resemblance? After all, seeing is not always believing. Large silvery predators swim in the depths of the sea; but, sharks are fish and dolphins are mammals. Bats, budgerigars, and bees all fly; but, these animals are mammals, avians, and insects, respectively.

In fact, there is no sure and simple way to discriminate profound from superficial resemblance. But, a hint from William James suggests how we might be able to do so.

\section{James}

America's first great psychologist, William James (1842-1910), long ago complained that "...it is the bane of psychology to suppose that where the results are similar, processes must be the same (1890, p. 528)". James clearly took exception to glibly agreeing with Montaigne's earlier adage that: From like results we must infer like faculties.

James underscored this interpretive problem by posing a hypothetical example: "Psychologists are too apt to reason as geometers would, if the latter were to say that the diameter of a circle is the same thing as its semi-circumference, because, forsooth, they terminate in the same two points" (1890, p. 528). This geometrical argument suggests a promising, practical solution to the problem of deciding whether the 
same process underlies similar behaviors in different organisms — a prime challenge of comparative psychology.

Suppose that we systematically vary some independent variable across many — not just two - different parametric values and we observe the effects of those variations on the behavior of different species of animals. Now, suppose that those parametric functions closely parallel one another. Most researchers would agree that such striking "parametric parallels" would be extremely unlikely to have arisen by chance; instead, those parallels suggest a common process at work in the different species. Thus, parametric study is not just workmanlike psychological science; it is absolutely vital to comparative behavioral study.

\section{Empirical research in comparative cognition}

We now turn to four domains of contemporary psychological science in which clear parametric parallels have been documented in humans and animals, thereby suggesting the operation of common processes in associative/causal learning, short-term memory, number discrimination, and metacognition. I selected these particular realms because they are basic to adaptive behavior and because they remain extremely active areas of investigation in comparative cognition.

\section{Associative/causal learning}

Causation is fundamental to all natural science. Many researchers have come to believe that identifying and verifying the interrelations between natural phenomena requires logical or statistical inference. If that were the case, then these processes might very well be uniquely human. David Hume (1711-1776) vigorously disagreed with this point of view.

For Hume, a purely mechanical associative process leads to the impression of causation. Furthermore, the same process operates in humans and animals. Why did Hume come to these two striking conclusions? Because, he said, survival cannot depend on the slowness and fallibility of logic and reason.

According to Hume, causal beliefs actually arise from the association of ideas. Because they develop from the repeated conjunction 
of events, associations must rise to their point of perfection by degrees. Thus, causal judgments should emerge progressively, as do associative learning curves. Empirical evidence shows that they do (Wasserman, Kao, Van Hamme, Katagiri \& Young, 1996).

Furthermore, causal beliefs cannot produce assurance in any single event as the cause unless it is frequently paired with the effect and unless it is superior to rival causes. Therefore, as in the case of associative cue competition, discounting of inferior rivals should occur in causal judgment. Is that so?

Several famous cue competition effects have been shown to occur in associative learning: the two most familiar are: blocking and overshadowing (Wasserman \& Miller, 1997). Yet another famous case of cue competition is the cue validity effect that was first reported by Wagner, Logan, Haberlandt, and Price (1968). Key to the cue validity effect is that Cue $\mathrm{X}$, the target cue, is equally often paired with the outcome in all of the conditions. Cues A and B are differently paired with the outcome in the various conditions.

Wasserman (1974) showed how control by Cues A, B, and X systematically changes as a function of the disparity in the probability of the outcome after Cues A and B. Wasserman gave pigeons 2-key compound stimuli and separately measured pecking at each element. The AX and BX trials occurred equally often. The correlation of Cues A and B with food varied across five different experimental conditions; but, Cue $\mathrm{X}$ was equally paired with food in all five of the conditions. Responding to Cue A rose as it was increasingly paired with food; responding to Cue B fell as it was decreasingly paired with food. Beyond these obvious effects, responding to Cue $\mathrm{X}$ fell as Cues $\mathrm{A}$ and $\mathrm{B}$ came to differentially predict the presentation and nonpresentation of food. In other words, despite Cue X having been paired with food $50 \%$ of the time in all of the conditions, the relative validity of Cues $\mathrm{A}$ and $\mathrm{B}$ dramatically affected responding to Cue $\mathrm{X}$ : the more valid were Cues $\mathrm{A}$ and $\mathrm{B}$, the less valid was Cue $\mathrm{X}$ and the less responding it prompted.

Was this cue validity effect limited to rats, rabbits, and pigeons in operant and respondent conditioning situations? To find out, the possibility 
of a cue validity effect in human causal judgment was analogously studied with an allergy diagnosis task by Wasserman (1990). College students had to rate the causal effectiveness of three possible allergens: shrimp, strawberries, and peanuts. The three allergens were given in two pairs: $\mathrm{AX}$ and $\mathrm{BX}$, just as in the earlier conditioning experiments with animals. The association of these compounds with a hypothetical patient's allergic reaction was varied across five different experimental conditions, just as in the prior pigeon project of Wasserman (1974).

The results were the same. Causal ratings of Cue A rose as it was increasingly paired with the allergic reaction. Causal ratings of Cue B fell as it was decreasingly paired with the allergic reaction. And, causal ratings of Cue X fell as Cues A and B came to differentially predict the occurrence and nonoccurrence of the allergic reaction.

Thus, causation and association are strongly related empirically. Both exhibit acquisition. Both exhibit cue competition. And, both phenomena can be explained by elementary associative principles. Reason is not necessary to explain either phenomenon.

In Hume's words, "Any theory, by which we explain the operations of the understanding, or the origin and connection of the passions in man, will acquire additional authority, if we find, that the same theory is requisite to explain the same phenomena in all other animals (1777/1951, p. 104)." Such a theory does seem plausible. A good candidate is the Rescorla-Wagner (1972) theory, which instantiates Hume's associative principles with an elegant mathematical model.

\section{Short-term memory}

Humans and animals alike can retain information for one-trialonly use for several seconds, thereby exhibiting short-term memory. Furthermore, when multiple items are to be retained, memory for those items often follows a characteristic function: initial items (primacy) and terminal items (recency) are better remembered than are items in the middle of the list. This familiar U-shaped function is called the serial-position effect.

Wright, Santiago, Sands, Kendrick, and Cook (1985) parametrically explored this serial-position effect in four different species: 
humans, rhesus monkeys, capuchin monkeys, and pigeons. To all species, Wright et al. showed lists of four visual stimuli —one after another- on the upper of two viewing screens. Next, they showed a probe item on the lower viewing screen after fourth list item had been removed. If the probe item had been in the list, then one button response produced reward; if the probe item had not been in the list, then a second button response produced reward. Any other button responses led to no reward being given.

All four species showed the serial-position effect. They did so at intermediate delays between the last list item and the two-button choice test. However, at short delays, all four species showed a continuously increasing memory function, with the last list item being the best remembered. And, at long delays, all four species showed a continuously decreasing memory function, with the first list item being the best remembered. These parametric parallels are truly remarkable and they strongly suggest that common memory processes are mediating all four species' behavior in this list memory task.

It is worth noting that these patterns of behavior were exhibited by all four species despite disparities in the visual stimuli that were shown and the retention intervals that were given. For example, the longest retention interval was $10 \mathrm{~s}$ for pigeons, it was $30 \mathrm{~s}$ for rhesus and capuchin monkeys, and it was $100 \mathrm{~s}$ for humans. So, quantitative differences in memory capacity may well exist. Yet, despite those quantitative differences, the nature of list memory may very well be the same.

\section{Number discrimination}

Both humans and animals can discriminate the number of items that are shown at any given time, attesting to stimulus control by this abstract environmental property. How similar is the number discrimination process in different species?

Cantlon and Brannon (2006) investigated this question in humans and rhesus monkeys. On each trial, two visual arrays containing different numbers (from 2 to 30) of small squares were shown. The task was to respond first to the array that contained fewer items. For monkeys, 
the report response was touching the smaller array, thereby activating a touch screen with a finger. For humans, the report response was bringing a cursor into contact with the smaller array by operating a computer mouse. The investigators measured: choice accuracy and reaction time.

The results for monkeys and humans were strikingly similar. As the smaller and the larger numbers of items were made more similar to one another - thereby increasing the difficulty of the numerical discrimination - accuracy fell and reaction time rose. These findings suggest that monkeys and humans each represent numbers as large as 30 as perceptual magnitudes and that they rely on a comparison process which closely accords with Weber's Law. Cantlon and Brannon suggest that the close parametric similarity in the behavior of monkeys and humans provides the strongest evidence to date of a single nonverbal, evolutionarily primitive mechanism for representing and comparing numerical values.

\section{Metacognition}

Since Descartes, philosophers have held that knowing one's own mind is central to consciousness. Is metacognition uniquely human? Do animals also know if and what they know? How can you tell if they do?

Several groups of researchers have studied metacognition in such diverse animals as rats, pigeons, monkeys, and dolphins (see Carruthers, 2008 for a review and critique). The earliest work with monkeys and humans was conducted by Shields, Smith, and Washburn (1997).

Monkey and human subjects were shown a visual display involving different densities of dots. If the display involved sparse dots, then subjects were to make one arbitrary report response to receive reward. If the display involved dense dots, then subjects were to make a second arbitrary report response to receive reward. The new twist to the experiment was that if subjects were uncertain as to which of the two responses to make, then they could make a third "uncertain" response, which provided a smaller, but more likely reward.

The pattern of results across a wide range of dot densities was very similar for monkeys and humans. As dot density rose, the probability of "sparse" reports fell and the probability of "dense" reports rose. Where the 
two functions crossed, subjects were most likely to make the "uncertain" response, with the probability of such responses declining to either side of that point.

Considerable controversy surrounds these findings, particularly whether they uniquely support a metacognitive interpretation (Carruthers, 2008; Smith, Beran, Couchman \& Coutinho, 2008). Nevertheless, one cannot help but be impressed by the close parametric parallels that hold here for monkey and human discrimination behavior.

\section{Overview}

My review of empirical research in comparative cognition discloses that clear parametric parallels exist between human and animal behavior. These parallels hold in such diverse realms as: associative/causal learning, short-term memory, number discrimination, and metacognition. These strong parametric parallels argue against superficial similarity and in favor of profound resemblance in the cognitive processes of humans and animals. Pursuit of further parallels surely seems warranted.

\section{Observations and analyses}

To organize my final observations and analyses, it will be useful to return to the three original questions from the 2003 New York Times that opened this paper.

\section{How does the brain work?}

Very well, indeed! Brains remember past, they act in present, and they prepare for the future. These and other cognitive functions enable organisms to adapt to the complex and ever-changing contingencies of survival to which they are ceaselessly exposed. Elucidating the biological mechanisms of cognition is the task of neuroscience.

Neuroscience has divulged that brains are not: hydraulic devices, telephone switchboards, or digital computers. Reducing brains to humanmade machines may have heuristic merit; but, 250 years of such efforts may have been far less fruitful than have direct studies of human and animal behavior and biology. 
Neuroscience has also revealed that brains are not intelligently designed. In his recent book, The Accidental Mind, David Linden (2007) persuasively argues that the human brain is a cobbled-together mess: a weird merger of ad hoc solutions that have accrued over millions of years of evolution. The brain's quirky, inefficient, and sometimes bizarre organization nevertheless functions quite impressively given its haphazard provenance.

Linden concludes that the brain is not an optimized, general problem-solving machine. It is clearly not the biological organ of reason —Descartes' so-called "universal instrument". Our "accidental brain", Linden claims, accounts for the very nature of human nature.

\section{Can robots become conscious?}

Opinion is certainly divided on this question. The prospect of conscious robots arises not only from science fiction, but from the philosophical notion of functionalism: the doctrine that what makes something a thought, a desire, or any other kind of mental state does not depend on its internal construction, but only on its function within the system of which it is a part. This notion permits other organisms or even machines with very different physical constitutions to have mental states if they too exhibit sufficiently similar behaviors.

So, can computers become conscious? I say "no". Nor can they digest food or fall in love. As simulacra, robots and computers are just not made of the "right stuff." Matter matters!

I have been challenged in my belief that computers cannot become conscious. Critics have contended that, if only we could properly mimic the organization of the nervous system — with silicon chips, plastic, or rubber bands - then consciousness would necessarily emerge.

I suspect that the very audacity of this claim makes it appealing to some. But, to me, it seems utterly preposterous. I know that philosophers have invented a number of clever thought experiments to support their functionalist position. I cannot claim to be half as clever as they are, but I have devised a simple thought experiment of my own. I call it the Martian mix.

Suppose that one of our future Mars probes drills down into the frozen Martian soil and gathers an interesting substance. The substance is 
returned to Earth where, at room temperature, it melts into a colorless, odorless liquid. The liquid freezes at 32 degrees $\mathrm{F}$ and it boils at 212 degrees F. It is composed of two elements that are unknown on Earth: call them $\mathrm{X}$ and $\mathrm{Y}$. The chemical formula for this liquid is found to be $\mathrm{X}_{2} \mathrm{Y}$. If I were offered this Martian mix to drink, then I would politely decline. To my functionalist friends, I would cheerfully say, "Salud!"

But, do not take my argument against computer consciousness as gospel. Consider as well these remarks of John Searle in a 2007 interview with the Boston Globe: "Defined by the manipulation of zeroes and ones, the computer model can tell us nothing about how our brains produce mind, consciousness, and a sense of self". At least I am in good company.

\section{Are animals smarter than we think?}

Of course! It is no simple task to investigate animal cognition. But, as our methods have improved, so too have our understanding and appreciation of animal intelligence (Wasserman \& Zentall, 2006b). Differences between humans and animals must exist: many are already known. But, they may be outnumbered by similarities.

I must thus conclude that humans and animals are highly related life forms which exhibit many complex cognitive processes. Parametric parallels suggest that common biological mechanisms lie at the root of their cognition and behavior. However, like Vaucanson's Duck, computers and other mechanical devices are pale replicas built from the "wrong stuff".

Nevertheless, pursuing Descartes' agenda of objectively studying humans and animals as if they were machines does have real merit. Robust laws of behavior and cognition are emerging from such study. For a natural science of mind, I see no reasonable investigative alternative.

So, I conclude that minding machines do exist; they are humans and animals. Minding mediates the complex changes in behavior that humans and animals exhibit. Minding's their business! Humans and animals are machines only insofar as their behaviors are products of biological mechanisms: we might call them "minding meat" or "meat machines" (Smith, 2005). As powerful as we may construct them, no artificial devices can ever duplicate nature's own minding machines. 


\section{References}

Adam, C. \& Tannery, P. (1908). Oeuvres de Descartes, Paris: Cerf.

Ariew, R. (2000). René Descartes: Philosophical essays and correspondence. Indianapolis, IN: Hackett.

Avramides, A. (1996). Descartes and other minds. Teorema, 16, 27-46.

Cantlon, J. F. \& Brannon, E. M. (2006). Shared system for ordering small and large numbers in monkeys and humans. Psychological Science, 17, 402-407.

Carruthers, P. (2008). Meta-cognition in animals: A skeptical look. Mind \& Language, 23, 58-89.

Descartes, R. (1632/1972). Treatise of man. French text with translation and commentary by T. S. Hall. Cambridge, MA: Harvard University Press.

Erion, G. J. (2001). The Cartesian Test for automatism. Minds and Machines, 11, 29-39.

Gunderson, K. (1964). Descartes, La Mettrie, language, and machines. Philosophy, 39, 193-222.

Hume, D. (1777/1951). Enquiries concerning the human understanding and concerning the principles of morals (2nd ed. edited by L. A. Selby-Bigge).

James, W. (1890). The principles of psychology (Vol. 1). London: Henry Holt $\&$ Co.

Kubinyi, E., Miklósi, A., Kaplan, F., Gácsi, M., Topál, J. \& Csányi, V. (2004). Social behaviour of dogs encountering AIBO, an animallike robot in a neutral and in a feeding situation. Behavioural Processes, 65, 231-239.

La Mettrie, J. O. D. (1747/1996). Machine man and other writings (translated and edited by A. Thompson). Cambridge: Cambridge University Press.

Linden, D. (2007). The accidental mind. Cambridge, MA: Belknap Press of Harvard University Press.

Melemy, H. (2005). Silencing the animals: Montaigne, Descartes, and the hyperbole of language. Symplokè, 13, 263-282.

Montaigne, Michel De. (1580/2003). The complete essays. Translated by M. A. Screech. London: Penguin.

Newman, L. (2001). Unmasking Descartes' case for the Bête Machine doctrine. Canadian Journal of Philosophy, 31, 389-426. 
Rescorla, R. A. \& Wagner, A. R. (1972). A theory of Pavlovian conditioning: Variations in the effectiveness of reinforcement and nonreinforcement. In A. H. Black \& W. F. Prokasy (Eds.), Classical conditioning II: Current research and theory (pp. 64-99). New York: Appleton-Century-Crofts.

Riskin, J. (2003a). Eighteenth-century wetware. Representations, 83, 97125.

Riskin, J. (2003b). The defecating duck, or, the ambiguous origins of artificial life. Critical Inquiry, 29, 599-633.

Shields, W. E., Smith, J. D. \& Washburn, D. A. (1997). Uncertain responses by humans and rhesus monkeys (Macaca mulatta) in a psychophysical same-different task. Journal of Experimental Psychology: General, 126, 147-164.

Silver, B. (2002). Montaigne, An apology for Raymond Sebond: Happiness and the poverty of reason. Midwest Studies in Philosophy, 26, 94110.

Smith, C. U. M. (2005). Book Review Essay. How the modern world began: Stephen Gaukroger's Descartes' system of natural philosophy. Journal of the History of the Neurosciences, 14, 57-63.

Smith, J. D., Beran, M. J., Couchman, J. J. \& Coutinho, M. V. C. (2008). The comparative study of metacognition: Sharper paradigms, safer inferences. Psychonomic Bulletin and Review, 15, 679-691.

Vartanian, V. (i993). Review of Wellman, K. (1992). La Mettrie: Medicine, philosophy, and the enlightenment. Durham, NC: Duke University Press.

Wagner, A. R., Logan, F. A., Haberlandt, K. \& Price, T. (1968). Stimulus selection in animal discrimination learning. Journal of Experimental Psychology, 76, 171-180.

Wasserman, E. A. (1974). Stimulus-reinforcer predictiveness and selective discrimination learning in pigeons. Journal of Experimental Psychology, 103, 284-297.

Wasserman, E. A. (1990). Attribution of causality to common and distinctive elements of compound stimuli. Psychological Science, 1, 298-302.

Wasserman, E. A., Kao, S.F., Van Hamme, L. J., Katagiri, M. \& Young, M. E. (1996). Causation and association. In D. R. Shanks, K. J. Holyoak, and D. L. Medin (Eds.), Psychology of Learning and Motivation: Causal Learning. San Diego: Academic Press. Pp. 207-264. 
Wasserman, E. A. \& Miller, R. R. (1997). What's elementary about associative learning? Annual Review of Psychology, 48, 573-607.

Wasserman, E. A. \& Zentall, T. R. (2006a). Comparative cognition: A natural science approach to the study of animal intelligence. In E. A. Wasserman \& T. R. Zentall (Eds.), Comparative cognition: Experimental explorations of animal intelligence. New York: Oxford University Press.

Wasserman, E. A. \& Zentall, T. R. (2006b). Comparative cognition: Experimental explorations of animal intelligence. New York: Oxford University Press.

Werrett, S. (200I). Wonders never cease: Descartes's Météores and the rainbow fountain. British Journal for the History of Science, 34, 129-147.

Wilson, M. D. (1995). Animal ideas. Proceedings and Addresses of the American Philosophical Association, 69, 7-25.

Wood, G. (2002). Living dolls: A magical history of the quest for mechanical life. Guardian Unlimited, February 16, 2002.

Wright, A. A., Santiago, H. C., Sands, S. F., Kendrick, D. F. \& Cook, R. G. (1985). Memory processing of serial lists by pigeons, monkeys, and people. Science, 229, 287-289.

Fecha de Recepción de artículo: 13 de agosto de 2009.

Fecha de Aceptación de artículo: 27 de septiembre de 2009. 